\title{
CONSUMO CONSCIENTE: O ANVERSO SUBJACENTE DA POLÍTICA NACIONAL DE RESÍDUOS SÓLIDOS
}

\begin{abstract}
Antônio Carlos Efing
Mestre e Doutor pela PUCSP; professor titular da PUCPR (Curitiba, PR-Brasil) onde leciona na graduação, especializações, mestrado e doutorado; professor da Escola da Magistratura do Paraná; membro do Instituto dos Advogados do Paraná; Advogado militante em Curitiba. ace@eradv.com.br
\end{abstract}

\section{Ana Paula Maciel Costa Kalil}

Doutoranda e Mestre em Direito Econômico e Socioambiental da PUC/PR. Professora orientadora nos cursos de Pós-Graduação em Direito Ambiental e em Economia e Meio Ambiente da UFPR (Curitiba, PRBrasil).

macielanapaula@hotmail.com

RESUMO: A sociedade de consumo hodierna vivencia um tempo de profunda reflexão, tendo em vista as várias sequelas causadas pela cultura do excesso e do descartável, dentre elas, em especial, o aumento na geração dos resíduos sólidos. Por meio de uma pesquisa bibliográfica, o objetivo deste artigo é evidenciar a chamada macrorrelação ambiental de consumo e a importância da Política Nacional de Resíduos Sólidos na harmonização desta relação, que incita, inclusive, o chamado consumo consciente. As exigências socioambientais emergentes passam a invocar a necessidade da incorporação dos valores ambientais em todos os aspectos do consumo, havendo uma maior preocupação com a responsabilidade pós-consumo, o que se reflete na escolha do consumidor.

PALAVRAS-CHAVE: Macrorrelação ambiental de consumo; Política Nacional de Resíduos Sólidos; Responsabilidade pós-consumo; Consumo consciente.

\section{Conscious consumption: the hidden face of the national policy of solid waste}

ABSTRACT: Today's consumer society experiences a moment of deep reflection in view of the various sequels caused by the culture of the excess and the disposable, among them, in particular, the increase of generation of solid waste. Through a literature review, the purpose of this article is to highlight the so-called environmental large relations of consumption and the importance of the National Policy on Solid Waste in the harmonization of this relationship, which encourages even the so-called conscious consumption. The emerging environmental requirements come to rely on the need to incorporate environmental values in all aspects of consumption, increasing the concern with post-consumer responsibility, which is reflected in the consumer's choice.

KEYWORDS: Environmental large relations of consumption; National Policy on Solid Waste; post-consumer responsibility; Conscious consumption.

Recebido em: 1 ago. 2016. Avaliado em: 04 e 21 nov. 2016. 


\section{INTRODUÇ̃̃o}

A atual sociedade de consumo vive momentos de profunda reflexão. É preciso repensar os atuais padrões de consumo e sua interferência no meio ambiente.

O presente trabalho, utilizando-se da metodologia de pesquisa de documentação indireta e fazendo uso de pesquisas bibliográficas e documentais, aborda a crescente demanda na busca do consumo consciente, uma vez que o consumidor deve ter discernimento da sua importância nas transformações econômicas, sociais e políticas. O consumidor deve usar seu poder de escolha para favorecer produtos e serviços ecologicamente corretos e com isso promover a sustentabilidade social e ambiental.

Para fazer face a esta novel demanda, e demonstrando uma verdadeira macrorrelação ambiental de consumo, a Política Nacional de Resíduos Sólidos, representa um avanço na proteção e preservação do meio ambiente na medida em que põe em evidência a imprescindível revisão dos padrões de produção e consumo da atualidade, assim como a necessidade de repensar e planejar o manejo e o gerenciamento adequados dos resíduos em todo o país, com a modificação do modus operandi até então arraigados na cultura omissiva e permissiva da sociedade. Instituiu, para tanto, uma série de mecanismos capazes incentivar e promover o consumo consciente.

A responsabilidade pelo descarte de produtos e destinação final de resíduos, então, também conhecida como "responsabilidade pós-consumo", passa a ser compartilhada entre todos os elos da cadeia produtiva. Uma nova consciência ecológica pressupõe mudanças urgentes nos comportamentos e hábitos de consumo, com um olhar voltado, não apenas à satisfação pessoal, mas principalmente à sustentabilidade.

Harmonizar a relação entre consumo e meio ambiente é o novo desafio que se instaura. Desse entrosamento resultará uma nova ética: a do consumo sustentável e consciente.

\section{Meio AMbiente e CONSUMo}

A Revolução Industrial não alterou apenas o modo de produção da sociedade, mas inaugurou uma nova sociedade, a sociedade de consumo, trazendo como consequência imediata e final, uma profunda alteração sobre o meio ambiente natural e social, a partir do momento em que os bens naturais deixaram de ser estritamente naturais para se tornarem apropriação do capital tecnologizado guiado pela racionalidade econômica (LEFF, Enrique, 2012, p. 98), assim como as relações sociais passam a ser guiadas também por essa racionalidade. Por isso, Baudrillard (2010, p. 81.) afirma que, durante o século XX o capitalismo mudou seu centro de gravidade, saindo do campo da produção para o do consumo, consignando este como o principal reino da atividade social, cristalizando, assim, o universo simbólico da sociedade de consumo.

Segundo Luckmann e Berger (2014, p. 130), o universo simbólico fornece o nível mais alto de integração para os significados discrepantes dentro da vida cotidiana da sociedade, na medida em que até mesmo aquele que se encontra em situações marginais de experiência, como a do consumidor falho, retorna à "realidade" criada pelo universo simbólico do consumo, uma vez que este passa a modular a identidade do indivíduo e gerar a pretensão de conquistar alguma felicidade instrumental, o que é legitimado pela ordem institucionalizada na sociedade.

Cria-se, portanto, a chamada sociedade líquido-moderna (BAUMAN, 2007, p. 17), na qual seus membros são tidos como inquietos e voláteis por não possuírem hábitos, rotinas ou uma forma de agir específica e única. Consequentemente, aquilo que não acompanha as rápidas mudanças da sociedade contemporânea passa a ser considerado como "lixo": 


\begin{abstract}
O lixo é o principal e, comprovadamente, o mais abundante produto da sociedade líquido moderna de consumo. Entre as indústrias da sociedade de consumo, a de produção de lixo é a mais sólida e imune a crises. Isso faz da remoção do lixo um dos dois principais desafios que a vida líquida precisa enfrentar e resolver. O outro é a ameaça de ser jogado no lixo. Em um mundo repleto de consumidores e produtos, a vida flutua desconfortavelmente entre os prazeres do consumo e os horrores da pilha de lixo (BAUMAN, 2007, p. 17).
\end{abstract}

A sequela desta mudança é o aumento da pressão sobre os bens naturais para atender a demanda do consumo. Com isso, tem-se que os riscos produzidos para atender a toda esta exigência, e que ameaçam o meio ambiente global, são hoje de uma escala e grau de incerteza sem precedentes na história.

Não resta dúvida, portanto, que foi consagrada a cultura do excesso, da urgência, da comodidade, do descartável e do lixo. Neste sentido, Baudrillard (2010, p. 39) ilustra:

[...] sabe-se muito bem como a abundância das sociedades ricas está associada com
o desperdício, já que foi possível falar de 'civilização do caixote de lixo' e encarar a
hipótese de fazer uma 'sociologia do caixote de lixo': Diz-me o que deitas fora e dir-
te-ei quem és! Mas a estatística da porcaria e do detrito não tem qualquer interesse;
constitui apenas o sinal redundante do volume de bens oferecidos e da respectiva
profusão.

Porém, a voracidade na produção de mercadorias e o ritmo veloz que se imprime ao consumo são inversamente proporcionais à capacidade de solucionar os problemas ambientais advindos destes processos de produção e consumo desenvolvidos, assim como superam, em muito, o tempo de recomposição do ambiente.

Na concepção de Ferreira (2008, p. 30) o modelo de desenvolvimento amparado nas dimensões ilimitadas do crescimento econômico mostrou-se alheio à justiça social e à prudência ambiental, provocando um abalo considerável na ideologia do progresso, prenunciando a chegada de tempos de crise generalizada.

Ao tratarem das questões socioambientais, Fernandes e Sampaio (2008, p. 87-94) fizeram uma análise geral sobre o significado de paradigma, a partir da obra de Thomas Kuhn. Para referidos autores, a ciência, assim como a sociedade são dinâmicas e interligadas. Por esta razão, o paradigma científico não está desconectado do paradigma predominante na sociedade, uma vez que a ciência produz e se reproduz para e a partir destas realidades naturais, culturais e sociológicas, motivo pelo qual não há que se falar em processo linear das teorias que as aperfeiçoam mutuamente.

A par destas breves considerações, os autores citados definem o paradigma como sendo "um conjunto de valores e regras socioculturais universalmente aceitos por algum tempo em uma sociedade ou grupo cultural, moldando e conduzindo as suas práticas" (FERNANDES; SAMPAIO, 2008, p. 87-94).

Tem-se, destarte, que os modelos, ou paradigmas não se prolongam infinitamente, o que significa dizer que, de tempos em tempos, quando o paradigma dominante não consegue mais responder adequadamente aos problemas por ele gerados, surgem alternativas a este modelo.

O que se percebe, portanto, é que o paradigma atual de sociedade, fundada na racionalidade econômico-científico-tecnológica, de cunho utilitarista e voltada para o consumismo desenfreado, está em crise, pois gerou uma série de problemas socioambientais, os quais não é capaz de resolver. 
Para Capella (1998), a crise do paradigma atual é uma crise da relação homem/natureza, mas numa complexidade muito mais ampla, cujo cerne está na sociedade de hiperconsumo e no modo de vida essencialmente voltado para fins econômicos.

Por isso que é sabido, e até em certo ponto retórico dizer, que a complexidade dos problemas socioambientais enfrentados ensejaram novas reivindicações pela sociedade, particularmente pela ênfase conferida à proteção do macrobem ambiental, passando a haver uma legítima preocupação com um comportamento ético e socioambientalmente responsável.

Na obra “A ética é possível num mundo de consumidores?”, Bauman (2011) examina as implicações dessa nova condição moderna de crise para questões da esfera pública, como a ética, o mercado e a democracia; e da esfera privada, como as decisões do consumo.

Para referido autor, numa sociedade em que se busca a satisfação individual em detrimento do coletivo, os argumentos de um contrato social altruísta (Rousseau) ou coercitivo (Hobbes) são solapados. Uma nova coerção, mais sutil, deixa o peso das escolhas sobre os ombros dos consumidores, na falta de uma governança eficiente que determine os limites éticos da economia de mercado. Por isso que, para Bauman (2011), é o pensar autônomo do sujeito esclarecido que enseja a mudança, ainda que contrárias às regras do jogo estabelecido.

Neste contexto, a proteção e a promoção do ambiente passam a despontar institucionalmente, como valor constitucional, capaz de instituir uma nova ordem pública por intermédio de um moderno programa jurídico-constitucional. Renuncia-se, então ao enfoque utilitarista, até então perseguido pela legislação, para adotar uma direção mais protecionista do meio ambiente, recepcionado de forma sistêmica.

O meio ambiente ecologicamente equilibrado é consagrado a direito fundamental, assegurando-o como um direito difuso, de uso comum do povo e essencial à sadia qualidade de vida, sendo ao mesmo tempo imposto, ao Poder Público e à coletividade, o dever de defendê-lo e preservá-lo para as presentes e futuras gerações.

Diante da realidade que se apresenta, soma-se, então, aos paradigmas da massificação ${ }^{1}$, da urbanização ${ }^{2}$ e da globalização ${ }^{3}$ o paradigma ambiental (socioambiental), no qual, segundo Lorenzetti (in MOROZINI, BARBOSA, 2010, p. 19):

\begin{abstract}
Neste cenário o individual não tem primazia e não rege a reciprocidade, já que é um conflito onde se afeta um bem comum. Nestes casos os direitos subjetivos devem ser interpretados de tal modo que não conspirem contra a deterioração de tais bens. [...] Em seu método, transita um caminho inverso aos anteriores, já que parte do coletivo para chegar ao individual. Por isso o paradigma ambiental também opera como metavalor, no sentido de que, assim como a liberdade, é um princípio organizativo de todos os demais.
\end{abstract}

Este novo paradigma, portanto, amolda-se como um verdadeiro guia para a interpretação lúcida das realidades orientadas pelos paradigmas citados, iluminando-os dentro de um contexto chamado "sociedade de risco"".

\footnotetext{
1 Massificação do consumo é a produção personalizada em massa, feita para atender a uma sociedade regida pelo hiperconsumo, que exige, além de uma rapidez frenética para atender ao turboconsumidor, estratégias de diversificação como a sedução (marketing), a inovação, as ofertas de conforto, a variedade e a renovação (leia-se obsolescência programada) capazes de suprir as necessidades que se apresentam.

2 Deslocamento das pessoas do campo para as cidades.

3 É a ideia de que há a intensificação das relações sociais planetárias, aproximando a tal ponto lugares afastados, que os eventos locais serão influenciados por ocorrências que estejam ocorrendo a milhares de quilômetros, e vice-versa, alterando significativamente os processos social, econômico, cultural e demográfico das sociedades.

4 A sociedade de risco é uma sociedade insegura, pois a proteção diminui na medida em que aumenta o próprio risco, isto quer dizer que nenhuma instituição ou ordem social está preparada para as consequências advindas, razão pela
} 
Estes novos conceitos e desafios, sobre os quais se discorreu, trazem consigo uma vigorosa abordagem que tem sido internalizada em várias esferas de atuação que tem vindicado, consequentemente, um olhar solidário, cooperativo e, principalmente, sistêmico.

No presente estudo, dar-se-á destaque à imbricação havida entre o consumo e os resíduos sólidos, que é uma discussão premente, tendo em vista ser fonte de inúmeros problemas socioambientais em todos os níveis local, regional e global.

\section{DA MACRORRELAÇÃO AMBIENTAL DO CONSUMO}

Ainda que por muitas ocasiões seu caráter seja simbólico, circunscrito de pouca efetividade, há que se destacar a evolução do arcabouço jurídico nacional na defesa destas duas figuras "vulneráveis", o consumidor e o meio ambiente.

Independentemente, e não excluindo, suas relevâncias e aplicações dentro de seus microssistemas (Código de Defesa do Consumidor e legislações esparsas ambientais), este trabalho se propõe a evidenciar a chamada macrorrelação ambiental de consumo, sendo esta compreendida não somente no âmbito individualista e direto do consumo stricto sensu, mas também na dimensão coletiva, difusa, ampla, relacional e contextual que envolve os atos de consumo e as agressões ao meio ambiente (MORAES, 2013, p. 118).

Ora, se a consequência primeira do consumo é impacto ambiental, considerando que o meio ambiente é afetado para atender à demanda do mercado consumidor, e a consequência última do consumo é, também, o impacto ambiental, já que o resultado final do consumo é o resíduo, e o aumento de um implica no aumento do outro, a disposição final do resíduo gerado pelo consumo afeta diretamente o meio ambiente, razão pela qual não há como dissociar a relação entre ambos.

Acontece que a crescente quantidade de produtos pós-consumo, fruto do crescimento acentuado da produção diversificada, assim como da redução de sua vida útil — obsolescência programada - exaure os sistemas tradicionais de disposição final, provocando poluição por contaminação ou por excesso.

Neste sentido é que há que se destacar a importância da Política Nacional de Resíduos Sólidos (Lei 12.305/2010) que se constitui, sem dúvida, em um marco legal histórico de exigência constitucional, compartilhando a corresponsabilidade pela gestão e gerenciamento dos resíduos sólidos entre os poderes estatais dos diferentes níveis federativos e entre os atores econômicos e sociais.

A partir do momento em que esta Lei estabeleceu como um de seus objetivos a não geração de resíduos ${ }^{5}$ e quando fixou a Logística Reversa ${ }^{6}$ como um dos instrumentos para se alcançar

qual negam estas ameaças afirmando a infalibilidade tecnológica frente às mesmas. (KALIL, Ana Paula Maciel Costa. Política Nacional de Resíduos Sólidos: o direito dos novos tempos. Curitiba: Juruá, 2015, p. 98).

5 Art. $7^{\circ}$ São objetivos da Política Nacional de Resíduos Sólidos: II - não geração, redução, reutilização, reciclagem e tratamento dos resíduos sólidos, bem como disposição final ambientalmente adequada dos rejeitos;

6 Art. $8^{\circ}$ São instrumentos da Política Nacional de Resíduos Sólidos, entre outros: III - a coleta seletiva, os sistemas de logística reversa e outras ferramentas relacionadas à implementação da responsabilidade compartilhada pelo ciclo de vida dos produtos; 
este objetivo, ela passou a interferir diretamente na sociedade de consumo ao vincular responsabilidades pelo ciclo de vida do produto, e a ensejar, ainda que em via transversa, o consumo consciente, uma vez que traz em seu bojo o conceito e o estímulo ao consumo sustentável ${ }^{7}$.

Segundo a própria Lei, em seu artigo $3^{\circ}$, inciso IV, ciclo de vida do produto "são as etapas que envolvem o desenvolvimento do produto, a obtenção de matérias-primas e insumos, o processo produtivo, o consumo e a disposição final".

Isso implica dizer que a responsabilidade socioambiental dos fornecedores e consumidores não se subsome apenas ao consumo em si. Passa-se, agora, e, ao menos em tese, a exigir um cuidado com toda a extensão do produto, questionando-se sua utilidade, validade, prestabilidade, necessidade, durabilidade, viabilidade e decorrente disposição final adequada.

A ausência da implantação e da execução de um sistema que garantisse esse cuidado com o pós-consumo, com os consequentes danos à vida urbana e ao meio ambiente, acabaram por induzir à sociedade a exigir a responsabilização das cadeias produtivas pelo equacionamento do retorno dos produtos.

Ainda que Paulo Valério Dal Pai Moraes (2013, p.115) se refira apenas à disposição final no que concerne à vida do produto, não tratando da primeira etapa que é a criação do próprio produto, suas considerações enredam as ideias aqui propostas:

\begin{abstract}
Posso dizer com tranquilidade que o ciclo de vida do produto traz a lume o conceito de macrorrelação ambiental de consumo, esclarecendo que, enquanto não se extinguir a vida do produto com a sua 'disposição final adequada', o que envolve também a respectiva embalagem, estará ele (o produto) irradiando efeitos e, portanto, tais efeitos, quando venham a causar danos a alguém, no caso, consumidores coletivamente considerados, induzirão ao reconhecimento de que são aplicáveis as legislações atinentes ao Direito do Consumidor em combinação com as Leis Ambientais (MORAES, 2013, p. 115).
\end{abstract}

Isso evidencia que os problemas ambientais gerados pelo consumo massificado nessa sociedade de risco não decorrem apenas do consumo em si, ou seja, da relação direta do consumidor que compra e usa e do fornecedor que vende e entrega. Nessa macrorrelação é necessária uma observação dos atos de produção dos produtos e serviços como um todo, isto é, no âmbito do espaço coletivo que acontecem.

Estabelece-se, portanto, uma nova ordem prioritária no art. $9^{\circ}$ da PNRS quando se fixa como meta primeira a "não geração de resíduos". Ela, por sua vez, marca uma revisão radical do modelo de produção e consumo, um verdadeiro rompimento com o paradigma vigente da obsolescência programada que demandará, inexoravelmente, uma mudança estrutural neste sistema e nos hábitos de consumo.

A revolução é que a própria lei tratou de viabilizar esta prioridade mediante a Logística Reversa (art. 3 XII; art. 333), ao instituir o lema "do berço ao berço", e não mais apenas a visão do "berço ao túmulo", possibilitando a redução do volume de resíduo gerado.

A concepção "do berço ao berço" foi criada para designar que os projetos de produtos, assim como seus processos produtivos possam ser feitos de forma a possibilitar que todos os

\footnotetext{
${ }^{7}$ Cf. "art. $3^{\circ}$. [...] XIII - padrões sustentáveis de produção e consumo: produção e consumo de bens e serviços de forma a atender as necessidades das atuais gerações e permitir melhores condições de vida, sem comprometer a qualidade ambiental e o atendimento das necessidades das gerações futuras".

8 O conceito Cradle to Cradle ou do berço ao berço, foi cunhado em 2002 pelo arquiteto americano William McDonough e o químico alemão Michael Braungart cujas ideias foram resumidas no livro Cradle do Cradle - Remaking the way we make things - publicado pela North Point Press. Em 2013, a obra ganhou edição em português, publicada pela Editora G. Gili, intitulada "Cradle to Cradle: criar e reciclar ilimitadamente".
} 
materiais utilizados para a fabricação do produto final sejam reaproveitados ou reutilizados em seu ou outro processo produtivo, após o seu descarte, o que estenderá a vida útil desses materiais, diminuindo a demanda por novos recursos naturais.

Neste sentido Patrícia Guarnieri (2011, p. 68-69) esclarece que:

[...] a logística reversa é totalmente compatível e atua no sentido de viabilizar a aplicação do modelo do berço ao berço, pois operacionaliza parte do que o modelo propõe: o retorno dos resíduos gerados nos processos produtivos e de vendas ao ciclo produtivo e/ou de negócios, analisando e implementando práticas que contribuam para a revalorização dos mesmos e preservação ao meio ambiente.

No entanto, para que a logística reversa se processe eficientemente é necessário que o produtor, distribuidor, varejista, consumidor final, coletor dos resíduos, selecionador, remanufaturador, reciclador, destinador final e o Estado estejam efetivamente envolvidos (LEITE, 2012, p. 346).

Vê-se, portanto, que a PNRS inova ao introduzir e disciplinar a responsabilidade compartilhada pelo ciclo de vida do produto no sistema de Logística Reversa, estabelecendo uma estratégia desafiante de conduzir a transição do controle passivo, com ordenamento jurídico protetivo/repressivo, para um controle ativo, com ordenamento promocional (BOBBIO, 2004, p. 367), imprescindível para incentivar e promover a transformação dos padrões insustentáveis para padrões sustentáveis de produção e consumo, baseando-se na cooperação, participação e mobilização sociais e na almejada construção da consciência e da cidadania ambiental.

Mesmo porque, conforme assinalam Leite e Ayala (2003, p. 88), há que se destacar a natureza dúplice do direito fundamental ao meio ambiente: na dimensão subjetiva que se refere ao direito da personalidade de proteção contra a degradação ambiental, direito este que pode ser exercido individual ou coletivamente, mas de forma solidária, por se tratar de um interesse difuso, daí porque se falar em "direito-função"; e na perspectiva objetiva que está ligado ao dever de proteção, cuja atribuição pertence ao Estado, a fim de preservar e restaurar os processos ecológicos essenciais; promover o manejo ecológico, assim como o de promover a educação ambiental em todos os níveis de ensino e a conscientização pública para a preservação do meio ambiente. Todavia, esse dever não exclui a responsabilidade da coletividade, já que o dever de proteção é também solidário.

Percebe-se, desta forma, o surgimento de um novo consumidor que confere maior valor aos aspectos de sustentabilidade ambiental e social, exigindo um comportamento estatal, empresarial e social compatíveis com estas expectativas.

\section{CONSUMO SUSTENTÁVEL E CONSUMIDOR PROATIVO}

Em apertada síntese, pode-se afirmar que a celeuma surgida a partir da publicação do Relatório Os Limites do Crescimento do Clube de Roma (THE CLUB OF ROME, 1968) em março de 1972, no qual demonstrou a contradição do crescimento ilimitado e irrestrito do consumo de material para atender ao mercado, em um mundo claramente finito de recursos, franqueou a discussão, que até os dias de hoje encontra-se aberta sobre o que é desenvolvimento sustentável, juntos ou apartados.

Em junho deste mesmo ano de 1972 aconteceu a $1^{\text {a }}$ Conferência das Nações Unidas sobre o Meio Ambiente Humano, no qual foram debatidos temas relativos ao desenvolvimento, crescimento econômico e proteção ambiental. A partir de então, o debate sobre desenvolvimento ganhou a devida intensidade em escala global. 
Posteriormente, no Relatório Nosso Futuro Comum, foi cunhado em 1987, pela Comissão Mundial sobre Meio Ambiente e Desenvolvimento, o conceito de desenvolvimento sustentável, como sendo aquele que satisfaz as necessidades do presente sem comprometer a capacidade das gerações futuras satisfazerem suas próprias necessidades.

Muitas discussões, controvérsias, teorias e posicionamentos foram tomados a partir destas duas ideias (ou será uma?), mas o pano de fundo que circunda toda essa discussão é a constatação de que a sociedade de consumo tem se mostrado deletéria em vários aspectos, e em particular, nos efeitos do consumo sobre o meio ambiente.

Em resposta a esta preocupação, na Conferência das Nações Unidas sobre o Meio Ambiente e o Desenvolvimento, realizada em junho de 1992, na cidade do Rio de Janeiro (Rio 92), foi aprovada, dentre outros documentos, a Agenda XXI, que abordou pela primeira vez, o tema "Mudança de Padrões de Consumo" no seu capítulo IV. Importante frisar que mesmo não sendo ela revestida pelo caráter da obrigatoriedade, ela foi "sancionada" pela comunidade internacional.

Seguindo este entendimento, Fátima Portilho (2010, p. 51) destaca que:

\begin{abstract}
Apesar de todos os embates travados, os documentos produzidos durante esta conferência, especialmente a Agenda 21, a Declaração do Rio e o Tratado das ONG's, começam a apontar a responsabilidade dos estilos de vida e consumo, principalmente das populações dos países do Norte, pela crise ambiental, inaugurando o segundo deslocamento discursivo que se quer enfatizar nesta análise: dos problemas ambientais causados pela produção para os problemas ambientais causados pelo consumo.
\end{abstract}

Neste documento se admite que uma das principais causas da deterioração do meio ambiente está nos padrões insustentáveis de produção e consumo. Por isso incita uma mudança comportamental na forma de consumir e produzir, assim como propõe que os governos devam estimular os consumidores a buscarem informações sobre as consequências das opções e comportamentos de consumo, de modo a estimular a demanda e o uso de produtos ambientalmente saudáveis.

O documento recomenda, ainda, um esforço conjunto entre governo, indústria e sociedade em geral, para reduzir a geração de resíduos e de produtos descartados. Estimulando, já em 1992, as seguintes ações: a) reciclagem nos processos industriais e do produto consumido; b) redução do desperdício na embalagem dos produtos; c) introdução de novos produtos ambientalmente saudáveis.

Instaura-se, portanto, o consumo sustentável, que segundo Portilho (2010, p. 138), é aquele que deve satisfazer as necessidades materiais e não-materiais das presentes e futuras gerações sem causar danos irreversíveis ao meio ambiente ou perda de função de sistemas naturais, havendo, portanto, uma preocupação com as necessidades humanas, com a distribuição social e com as futuras gerações.

Entre a Agenda XXI e os dias atuais, várias foram as ações e políticas públicas implementadas e incentivadoras da prática do consumo sustentável, assim como tornou-se muito forte a atuação da sociedade civil organizada e ONG's ligadas a esta questão, a exemplo do Instituto $\mathrm{Akatu}^{9}$, Instituto Lixo Zero ${ }^{10}$, os e próprios programas e políticas desenvolvidas pelo Ministério do Meio Ambiente ${ }^{11}$, que, segundo este último, o faz por meio do Plano de Ação para a Produção e Consumo Sustentáveis, senão vejamos:

\footnotetext{
9 www.akatu.org.br

${ }^{10}$ www.ilzb.org

${ }^{11}$ Disponível em: <http://www.mma.gov.br/responsabilidade-socioambiental>. Acesso em: 13 de jun. de 2016.
} 


\begin{abstract}
O Plano de Ação para a Produção e Consumo Sustentáveis é uma ação do MMA que tem o objetivo de fomentar políticas, programas e ações que promovam a produção e o consumo sustentáveis no país.

Enfoca em seis áreas principais: Educação para o Consumo Sustentável; Varejo e Consumo Sustentável; Aumento da reciclagem; Compras Públicas Sustentáveis; Construções Sustentáveis e Agenda Ambiental na Administração Pública (A3P). Esse último programa incentiva a incorporação de atitudes sustentáveis na rotina dos órgãos públicos do país.
\end{abstract}

Recentemente, no final de 2015, foram aprovados pela Conferência das Nações Unidas sobre Desenvolvimento Sustentável $($ Rio+20) os "Objetivos do Desenvolvimento Sustentável ODS" que vieram substituir os "Objetivos de Desenvolvimento do Milênio - ODM", adotando a "Agenda 2030 - Transformando Nosso Mundo", sendo anunciados 17 Objetivos de Desenvolvimento Sustentável e 169 metas, que estraram em vigor no dia $1^{\circ}$ de janeiro de 2016 e orientarão as decisões a serem tomada ao longo dos próximos quinze anos.

De acordo com José Eli da Veiga (2015, p. 23):

\begin{abstract}
Sejam quais forem seus méritos e possíveis defeitos, além de reverterem o lado abstrato da noção de desenvolvimento sustentável, os ODS darão início a uma real aproximação das governanças do desenvolvimento e do meio ambiente, que permaneciam demasiadamente autônomos e distantes desde junho de 1972, quando o mundo começou a se dar conta do tamanho dessa encrenca na Conferência das Nações Unidas sobre o Meio Ambiente Humano.
\end{abstract}

Segundo o documento, os ODS e metas são integrados e indivisíveis, de natureza global e universalmente aplicáveis, tendo em conta as diferentes realidades, capacidades e níveis de desenvolvimento nacionais e respeitando as políticas e prioridades nacionais.

Ressalte-se que, em que pese vários objetivos tratem de maneira transversal da questão do consumo consciente e sustentável, o documento traz explicitamente em seu Objetivo 12 o escopo de "Assegurar padrões de produção e de consumo sustentáveis", e em suas 11 metas, tratando especificamente da questão dos resíduos gerados pelo consumo.

Também se mostra essencial falar da Carta Encíclica Laudato Si - sobre o cuidado da casa comum, também publicada em 2015, na qual o representante máximo da Igreja Católica, o Beato Papa Francisco, suscita a todos os seres humanos, entre outras questões não menos importantes, da necessidade do cuidado com o meio ambiente, vinculando, em várias passagens da Encíclica, os problemas enfrentados na atualidade com os padrões insustentáveis de produção e consumo.

Ademais, importante destacar que em seu Capítulo I, a primeira questão suscitada foi a dos resíduos, tamanha é a dimensão dos dados decorrentes de sua destinação e disposição inadequada:

\begin{abstract}
Devemos considerar também a poluição produzida pelos resíduos, incluindo os perigosos presentes em vários ambientes. [...] Estes problemas estão intimamente ligados à cultura do descarte, que afeta tanto os seres humanos excluídos como as coisas que se convertem rapidamente em lixo. [...] O sistema industrial, no final do coclio de produção e consumo, não desenvolveu a capacidade de absorver e reutilizar resíduos e detritos. Ainda não conseguiu adotar um sistema circular de produção que assegure recursos para todos e para as gerações futuras e que exige limitar, o mais possível, o uso dos recursos não renováveis, moderando o seu consumo, maximizando a eficiência no seu aproveitamento, reutilizando e reciclando-os. [...] A humanidade é chamada a tomar consciência da necessidade de mudanças de estilos de vida, de produção e de consumo.
\end{abstract}

Portanto, consoante Efing e Serraglio (2016, p. 220-249), o consumo sustentável se tornará efetivo a partir da reinvenção de meios capazes de harmonizar a relação dos indivíduos com 
o meio ambiente. Para isso, torna-se imprescindível que os consumidores assumam valores, como a responsabilidade, a solidariedade, a precaução e a participação, princípios esses que alicerçam o desenvolvimento sustentável.

Para Trajano (2011, p. 237-239), o consumo sustentável ainda se justifica no princípio da sustentabilidade, como princípio implícito de direito do consumidor decorrente da proteção da dignidade da pessoa humana e da cidadania, previstas no art. $1^{\circ}$, incisos II e III da Constituição Federal de 1988, e que traz a base para o consumidor realizar escolhas conscientes em termos de impactos socioambientais.

No entanto, mesmo diante de toda evolução, é preciso ter em mente que ainda estamos longe de uma solução satisfatória, principalmente considerando que muitas das ações e políticas têm se voltado às práticas de incentivo à reciclagem, como se esta fosse a panaceia para os problemas relacionados aos resíduos.

Há que se sobrelevar que, muitas das vezes, este tipo de ação está mais para um incentivo perverso ao consumo, que necessariamente ao consumo sustentável.

Até porque, a ênfase dada às políticas nas ações de reciclagem contraria a própria ordem de prioridades estabelecida pela PNRS, na qual a reciclagem aparece apenas em quarto lugar. A não geração é que se configura como prioridade máxima, o que exigirá, uma completa e absoluta reformulação do mercado, não só em relação ao design de produtos, mas da própria lógica da economia. Não é sem razão que todos os setores, tanto públicos, quanto privados passarem ao largo desta prescrição.

Mas este é um caminho sem volta. Por mais que se busque contornar certas adequações irrefutáveis, chegará o momento de enfrenta-las. E uma das formas mais eficazes de se fazer esse enfrentamento é pela tomada de consciência do consumidor de seu poder de persuasão na mudança dos hábitos de consumo que forçarão, consecutivamente, a mudança nos padrões de produção.

\section{CONSUMIDOR PROATIVO}

No aspecto macro, muitas medidas estão sendo tomadas, ainda que paulatinamente. Mas no aspecto micro, caberá ao consumidor a tarefa essencial de, com sua atitude proativa, estimular e reverberar esta novidade que é a preocupação com a geração de resíduo, empenhando-se em reduzi-lo.

Não apenas medidas governamentais e da comunidade internacional são importantes, mas são igualmente decisivos os hábitos e as escolhas dos consumidores, principalmente considerando a força da mídia social que espraia, numa velocidade jamais experimentada, informações que podem ser fatais ao sucesso de algum produto ou serviço.

Partindo de gestos bastante simples, como a providência de, ao comprar, recusar ou evitar a enorme quantidade de embalagens que costumeiramente são utilizadas para proteger e transportar qualquer produto, ou mesmo escolher um produto retornável, percebe-se que o poder de escolha do consumidor tem força vinculante. 
Segundo Oscar Ivan Prux ${ }^{12}$, o consumidor proativo busca se informar, reflete para se conscientizar, esforça-se para disciplinar seus hábitos e labora para apoiar e dar preferência a produtos e serviços de qualidade voltados ao consumo sustentável, utilizando produtos de empresas cujos processos produtivos sejam ambientalmente responsáveis, além de consumirem menos energia e que conduzam para a menor quantidade de resíduo final. Não comprar o que contribui para esta poluição, é a melhor estratégia para chegar-se a uma boa solução.

$\mathrm{O}$ Instituto $\mathrm{Akatu}^{13}$ nos informa que consumo consciente é aquele que se leva em consideração os impactos causados pelo consumo, o qual pode ser resumido em três máximas: a) consumir diferente: em que o consumo não é um fim em si mesmo; b) consumir solidariamente: buscando o bem-estar da sociedade e do meio ambiente; c) consumir sustentavelmente: deixando um mundo melhor para as próximas gerações.

Mas para se praticar o consumo consciente é essencial que a sociedade seja mais e melhor informada, sob pena de se inviabilizar tal prática. Nestes termos Efing (2002, p. 91) complementa que:

\begin{abstract}
O princípio da informação pode ser interpretado de várias formas, todas elas percucientemente alentadoras da efetivação dos interesses do consumidor. Seja a informação de cunho educacional, no sentido de conscientização dos consumidores acerca da busca de seus interesses, ou em relação à informação sobre os produtos e serviços colocados à disposição no mercado de consumo, bem como informações específicas que influenciem em relações de consumo coligadas.
\end{abstract}

Não é sem razão que a PNRS estabelece como um de seus princípios, o direito da sociedade à informação e ao controle social (art. $\left.6^{\circ}, \mathrm{X}\right)$.

De posse de informações relevantes e fidedignas, o consumidor pode, por meio de suas escolhas, buscar maximizar os impactos positivos e minimizar os negativos de seus atos de consumo e desta forma contribuir ativamente com seu poder de escolha para transformar a sociedade de hiperconsumo em uma sociedade sustentável. Praticar consumo consciente consiste numa atitude de liberdade de escolha e de protagonismo da própria existência.

\title{
CONCLUSÃo
}

Neste contexto, pode-se concluir o quanto se revela fundamental a instituição de políticas públicas, como a Política Nacional de Resíduos Sólidos que, por seus mecanismos, como a logística reversa, entre tantos outros, inaugura um novo modelo de gestão e gerenciamento dos resíduos sólidos que, mais que solucionar o problema da disposição final adequada, intenta educar para o consumo, incentivando e até instruindo os consumidores a respeito das características e peculiaridades dos produtos e serviços, capacitando-os para uma postura proativa de exercício dessa faceta da cidadania, tornando-os cada vez mais conscientes.

Trata-se, efetivamente, de uma mudança de paradigma em que indivíduo/consumidor e comunidade se veem como inter-relacionados e interdependentes na busca pela concretização de uma vida humana digna e com qualidade ambiental a todos os seus membros. Para tanto, abandona-se o controle eminentemente passivo, em que as obrigações de proteção eram apenas do Estado, para o controle ativo exercido por meio da responsabilidade compartilhada entre Estado e sociedade. Este modelo se propõe a promover a transformação dos padrões insustentáveis para

\footnotetext{
${ }^{12}$ Disponível em: <http://www.parana-online.com.br/colunistas/direito-consumidor/41414/A+EDUCA$\mathrm{CAO}+\mathrm{DO}+\mathrm{CONSUMIDOR}+\mathrm{PRO}+\mathrm{ATIVO}+\mathrm{EM}+\mathrm{PROL}+\mathrm{DO}+\mathrm{CONSUMO}+$ SUSTENTAVEL. Acesso em: $13 \mathrm{de}$ jun. 2016.

${ }^{13}$ Disponível em: www.akatu.org.br.Acesso em: 13 de jun. 2016.
} 
padrões sustentáveis de produção e consumo, com base na cooperação, participação e mobilização sociais para a construção da consciência e cidadania ambiental.

Para tanto, a todo tempo, o consumidor precisa ser informado e educado para compreender os processos de produção, de comercialização e as naturais consequências do consumo.

É a consagração da transversalidade do ambiente sobre as relações de consumo ou a macrorrelação ambiental de consumo, onde se busca uma ponderação ecológica de interesses na busca do consumo sustentável.

O consumidor, então, deixa de exercer apenas um papel passivo para atuar ativamente nas decisões do mercado ao refletir responsavelmente sobre os produtos e serviços que adquire.

A escolha consciente do consumidor abrange os aspectos socioambientais dos produtos e serviços dispostos no mercado, quais sejam, a opção de compra daqueles que verdadeiramente revelem menor potencialidade de geração de danos ao meio ambiente ecologicamente equilibrado e à sadia qualidade de vida.

Abre-se, portanto, a possibilidade de organizar um processo de produção a partir do desenvolvimento de forças ecológicas e das tecnologias sociais de produção que estão mais comprometidas com a satisfação das necessidades básicas e com a qualidade de vida das pessoas, a partir de um consumo cada vez mais consciente.

\section{REFERÊNCIAS}

BAUDRILLARD, Jean. A sociedade de consumo. 2. ed. Lisboa: Edições 70, 2010.

BAUMAN, Zygmunt. Vida líquida. Rio de Janeiro: Jorge Zahar, 2007.

. A ética é possível num mundo de consumidores? Traduzido por Alexandre Werneck. Rio de Janeiro: Jorge Zahar, 2011.

BOBBIO, Norberto. A era dos direitos. Rio de Janeiro: Elsevier, 2004.

CAPELLA, Juan Ramón. Os cidadãos servos. Porto Alegre: Sérgio Antônio Fabris, 1998.

FERNANDES, Valdir; SAMPAIO, Carlos Alberto Cioce. Problemática ambiental ou problemática socioambiental?: a natureza da relação sociedade/meio ambiente. Desenvolvimento e Meio Ambiente, n. 18, p. 87-94, jul./dez. 2008.

FERREIRA, Heline Sivini. A biossegurança dos organismos transgênicos no direito ambiental brasileiro: uma análise fundamentada na teoria da sociedade de risco. 2008. $368 \mathrm{f}$. Tese (Doutorado em Direito) — Universidade Federal de Santa Catarina, Florianópolis, 2008.

EFING, Antônio Carlos. Direito das relações contratuais 1. Curitiba: Juruá, 2002.

; SERRAGLIO, Diogo Andreola. O direito do consumo voltado à sustentabilidade: uma análise a partir da carta encíclica Laudato Si' sobre o cuidado da casa comum. Revista de Direito Econômico e Socioambiental, Curitiba, v. 7, n. 1, p. 220-249, jan./jun. 2016.

GUARNIERI, Patrícia. Logística reversa: em busca do equilíbrio econômico e ambiental. 1. ed. Recife: Clube de Autores, 2011.

LEFF, Enrique. Aventuras da epistemologia ambiental: da articulação das ciências ao diálogo dos saberes. Tradução de Silvana Coucci Leite. São Paulo: Cortez, 2012. 
LEITE, José Rubens Morato; AYALA, Patrick de Araújo. Dano ambiental: do individual ao coletivo extrapatrimonial. 2. ed. rev. atual. e ampl. São Paulo: Revista dos Tribunais, 2003.

LEITE. Paulo Roberto. Logística reversa na atualidade. In: JARDIM, Arnaldo; YOSHIDA, Consuelo; MACHADO FILHO, José Valverde (Eds.). Política Nacional, Gestão e Gerenciamento de Resíduos Sólidos. Barueri: Manole, 2012, (Coleção Ambiental).

LUCKMANN, Thomas; BERGER, Peter 1 . A construção social da realidade. Petrópolis: Vozes, 2014.

MORAES, Paulo Valério Dal Pai. Macrorrelação ambiental de consumo: responsabilidade pós-consumo ou relação coletiva de consumo?. Porto Alegre: Livraria do Advogado, 2013.

MOROZINI, Fábio Costa; BARBOSA, Fernanda Nunes. Teoria Geral do Direito Ambiental. São Paulo: Revista dos Tribunais, 2010.

PORTILHO, Fátima. Sustentabilidade ambiental, consumo e cidadania. São Paulo: Cortez, 2010.

TRAJANO, Fábio de Souza. O princípio da sustentabilidade como princípio fundamental constitucional e das relações de consumo. Revista Luso-Brasileira de Direito do Consumo, Curitiba, Bonijuris, n. 3, v. 1, p. 237-239, set. 2011.

VEIGA, José Eli da. Para entender o desenvolvimento sustentável. São Paulo: Editora 34, 2015. 